\title{
EL PROYECTO DE ACTO LEGISLATIVO 192 DE 2012 Y EL DERECHO INTERNACIONAL.
}

\author{
Rafael Arturo Prieto Sanjuán, Ph.D.*
}

Buenas tardes a todos ustedes, muchas gracias al Doctor Fernando; con el cariño y la confianza, el respeto y la admiración que le debo: muchísimas gracias por haber impulsado este Panel. Mil gracias a la Universidad Sergio Arboleda; ese mismo cariño que profesan por la Universidad Javeriana es el que también les tenemos allá, así como las preocupaciones que compartimos en el día de hoy. Quisiera rendir además un saludo muy especial a la mesa principal y a todos ustedes, por esta preocupación legítima, reveladora del interés que tiene tanto la sociedad civil como la academia, en los asuntos militares, pero especialmente, en el marco de la reforma al fuero militar. Creo que es uno de los proyectos que en mucho tiempo no vinculaba a tantas personas y a tantos sectores. Celebro no solamente la preocupación que existe en nuestro país, sino también en el seno de los organismos internacionales y los no gubernamentales por la defensa y protección de los Derechos Humanos.

Noté que en seguida de mi comunicación, el Coronel Javier Ayala presentará una acerca de "por qué investigar en el mundo del Derecho Internacional Humanitario", y pensaba en el gran riesgo de privarlo de cierta parte del contenido de lo que él tendría ya preparado. Pero realmente no es así. ¿Por qué? Porque el tema para el cual se me ha invitado a disertar durante los próximos 20 minutos

* Transliteración revisada por el panelista, a cargo del Egresado de la Escuela de Derecho y Monitor adscrito al Departamento de Derecho Penal, LuIS CAMILO PérEZ DUARTE. 
es el relativo al proyecto de Acto Legislativo en discusión, pero con relación al Derecho Internacional. Entonces, lo que me parece más importante es que en este plano, formule de mi parte la cuestión relativa a las fuentes de esta rama del Derecho. Porque en nuestro medio, en Colombia, como en otras partes del mundo, se usa y se abusa del Derecho Internacional, sin que corresponda a la traducción de lo que realmente significa. Hecha esta aclaración, mi charla estará orientada desde el punto de vista de un internacionalista, de un abogado internacionalista.

En ese sentido, les propongo que después de la introducción abordemos algunos temas de Derecho Internacional general, así como otras subcategorías. Esto nos permitirá hacer la distinción entre lo que es el régimen del Derecho Internacional Humanitario $y$, particularmente, los mecanismos de sanción de "infracciones graves", así denominadas por los cuatro Convenios de Ginebra de 1949 y el Protocolo Adicional I, frente a una institución que va creciendo, que va madurando, quizás un poco como en la artística locura de Picasso, con extraordinarias, pero difíciles e indefinidas formas como aquella a la que denominamos Crímenes de Lesa Humanidad. De hecho, considero que es la confusión entre las primeras y los segundos donde reside la incomprensión, al igual que los problemas de interpretación y aplicación del Derecho Internacional y, por esa vía, del concepto y contenido del fuero penal militar.

\section{De LA INCOMPRENSIÓN DEL DERECHO INTERnACIONAL.}

En ese orden de ideas, debemos hacer una distinción en Derecho Internacional Público, teniendo presente que una de sus ramas más importantes es la relativa a la protección de los seres humanos. En ese sentido, suele hacerse una diferencia que consiste en referirse, por una parte, al régimen de protección, Derecho o sistema Internacional de los Derechos Humanos. De manera muy reduccionista, este régimen se ocuparía solamente de aquellas violaciones contra las personas, "en tiempos de paz", mientras que, por otra parte, el Derecho Internacional Humanitario trataría sólo la cuestión de la protección de la persona en situaciones especialmente delicadas como las planteadas por los conflictos armados.

Así las cosas, tenemos que identificar primero cuáles son las fuentes del Derecho Internacional, y de estas dos subespecialidades en particular. Dichas fuentes son, antes que nada, los tratados internacionales. Es ésta 
la precisión que me parece necesario formular en estos instantes, por cuanto el Derecho Internacional -por lo menos el Derecho Internacional convencional- se refiere muy poco o nada al fuero militar. Primer punto de partida.

La segunda fuente, no necesariamente en orden de jerarquía, sino en el de presentación del Art. 38 del Estatuto de la Corte Internacional de Justicia, es la costumbre internacional. Este punto resulta de la mayor importancia, toda vez que, en el lenguaje de la ONU, así como en el que emplean los órganos del Sistema Interamericano de protección de Derechos Humanos, en el de las organizaciones tanto intergubernamentales como no gubernamentales, e incluso en el de algunos expertos, se hace referencia -no sé si a título de una tercera fuente- a lo que se ha dado en llamar estándares internacionales. Es por ello que quisiera preguntar: ¿qué son los estándares internacionales? ¿Es la misma costumbre internacional...? O simplemente los estándares serían una práctica general, jurídicamente no vinculante, una especie de soft law. Porque si nos ubicamos en un plano jurídico, entre las fuentes formales del Derecho Internacional sólo contamos en sentido estricto con los tratados internacionales, la fuente formal por excelencia por su modo de creación y, enseguida, con la costumbre internacional; si se quiere, aquella norma que no es el producto, por lo menos no solamente de un tratado internacional, sino que es el reflejo de una práctica constante, sistemática y generalizada, con una opinio iuris que le acompaña, es decir, con la creencia de que esa regla o esa práctica es vinculante, tanto, como si fuera un tratado internacional.

Entonces, ¿qué significan los "estándares internacionales"? Eso no lo puedo responder, porque francamente no lo sé. Si ustedes me lo permiten, lo que sí puedo plantear, con conocimiento de causa, son algunas reflexiones a partir del Derecho Internacional vigente o positivo. A ese propósito, sabemos que contamos con dos fuentes particularmente importantes. En el campo del derecho convencional o del derecho de los tratados, sin duda alguna debemos referirnos a los cuatro Convenios de Ginebra de 1949 y a sus dos Protocolos adicionales, destinados a proteger las personas en situaciones de conflicto armado. Ahora bien, en materia de costumbre internacional tenemos, sobre todo los países de sistema romano-germánico, una dificultad mayor, que es la norma no escrita. ¿Cómo se introduce este tipo de norma en nuestro ordenamiento interno? ¿por vía legal, cuando el constituyente o el legislador dicen: "mire, voy a adoptar 
esta norma que no aparece en ningún tratado pero que para nosotros tendrá el valor de ley, o por vía jurisprudencial...? Lo que haría surgir inmediatamente una importante discusión, a saber, ¿cuál es la competencia o el poder que tiene el juez para crear normas aferrándose a "estándares internacionales", no necesariamente convencionales, sino como resultado de la interpretación de una práctica internacional, real o pretendida, que se incorpora como derecho en el ordenamiento jurídico interno?

El caso concreto e ilustrativo del problema es el del uso de la noción de Crímenes de Lesa Humanidad. Por supuesto, hay comportamientos que encontramos en el Código Penal que corresponden con lo que buena parte de la sociedad internacional conoce con dicha denominación o categoría, pero no tenemos un título, capítulo o lista en nuestro Código Penal donde se tipifiquen los llamados Crímenes de Lesa Humanidad. Si ustedes dan "Ctrl $+\mathrm{F}^{\text {" a }}$ un documento en PDF o en HTML, o "Ctrl+B" a un documento en Word que contengan nuestro Código, y colocan dicha expresión, no la van a encontrar. Recordemos que la construcción confusa e incoherente de la noción de Crímenes de Lesa Humanidad en Colombia, ha sido esencialmente atribuida a la Fiscalía o a la Magistratura en ciertos casos de trascendencia nacional. Más aún, en algunos casos se ha empleado simplemente para evitar que no prescriba la acción penal sobre ciertos delitos. Pero muy pocas veces se ha hecho con fundamento en la sistematicidad o generalidad del ataque contra la población civil, como se estableció en el Estatuto de la Corte Penal Internacional, sino, de manera selectiva, bien sea porque la víctima tenía un reconocimiento o una importancia social o política, por ejemplo. Empero, crímenes mucho más difíciles de aceptar a nuestros ojos, por el grado de barbarie o de sevicia, seguramente no van a constituir un crimen de lesa humanidad en el campo penal, de acuerdo con el ordenamiento jurídico actual.

¿Cómo calificarían ustedes el crimen de la señora que es encontrada torturada y al borde de la muerte en el Parque Nacional, y que finalmente fallece como consecuencia de las lesiones y la infección generalizada de sus órganos internos? Yo diría, como ciudadano -no como abogado- eso es un Crimen de Lesa Humanidad, un crimen horrendo. Pues bien, en la calificación de un juez, de acuerdo con la normativa vigente, difícilmente podría calificarlo de Crimen de Lesa Humanidad si no demuestra la sistematicidad o la generalidad del ataque, es decir, que detrás de ello haya una política sistemática 
o generalizada de atacar, digamos, un grupo particularmente identificado por su género. Pero este tipo de análisis o hipótesis no se están realizando en nuestro país, comenzando por la inexistencia legal del contexto como elemento necesario del tipo penal. Esas construcciones dogmáticas, si prefieren, se están haciendo en tribunales internacionales, con un gran esfuerzo y trabajo académicos, en medio de un debate no exento de críticas; pero al fin y al cabo, es ese esfuerzo de reflexión jurídica el que ha permitido finalmente que en el Estatuto de la Corte Penal Internacional se haya llegado a identificar una lista casi que taxativa de Crímenes de Lesa Humanidad.

\section{LA CONFUSIÓN ENTRE CRÍMENES DE LESA HuMANIDAD Y CRÍMENES DE Guerra.}

Ahora bien, es importante señalar que los Crímenes de Lesa Humanidad, en cuanto al acto, pueden coincidir con ciertos Crímenes de Guerra, en el lenguaje del Estatuto de la Corte Penal Internacional, que tampoco nos dice nada sobre el fuero penal militar. Dicho Estatuto califica determinados comportamientos como Genocidio, como Crímenes de Guerra o como Crímenes de Lesa Humanidad y, esperando que algún día entre en vigor, como crimen de Agresión, pero atendiendo en cada caso, a determinadas circunstancias o condiciones.

En cuanto al Derecho Internacional Humanitario -seguramente el Coronel AyaLA tendrá la oportunidad de profundizar-tampoco se hace mayor precisión sobre la distinción o repartición de competencias de los tribunales en el orden interno. Si examinamos los cuatro Convenios de Ginebra de 1949 y el Protocolo adicional, la obligación fundamental que va a inspirar todo el sistema de Derecho Internacional Humanitario es la de respetar y hacer respetar las obligaciones allí contenidas (Art. $1^{\circ}$ común a los cuatro Convenios de Ginebra). Y luego, en términos simples, la parte de aplicación y sanciones de este régimen se traduce en el compromiso de cada Estado a respetar y a hacer respetar el DIH, particularmente en las filas de sus fuerzas militares, pero no nos dice nada sobre el fuero en particular. De pronto, el Convenio número tres, sobre prisioneros de guerra (en un conflicto internacional), es más preciso, porque se basa en la idea de que se trata de combatientes regulares en poder del enemigo, pero, en general, no hay una indicación específica sobre cuáles son las jurisdicciones competentes; por lo menos no hay una obligación como tal, por lo que cada Estado 
queda en libertad de adoptar el tipo de medidas que considere más adecuadas para cumplir con la obligación de respetar y hacer respetar las normas convencionales.

Lo que sí existe, es una lista de infracciones graves, así denominadas, en el Convenio número uno, en el dos, en el tres, en el cuatro, y en el Protocolo I, que condensa, de alguna manera, los cuatro anteriores. Sin embargo, no contamos con una lista de infracciones graves en el Protocolo II, sobre la protección de las víctimas de los conflictos armados no internacionales. Se requiere entonces que dichas infracciones sean incorporadas, así sea con una denominación diferente, en el orden interno a fin de dar cumplimiento a las obligaciones contraídas con dichos tratados. Y aún así, como abogado, en nuestro sistema, difícilmente podría defender una posición diferente a la que me brinda esencialmente el derecho escrito. La interpretación y recepción del derecho consuetudinario será una labor de identificación que corresponde al juez, si tiene consciencia de que la fuente del Derecho no es exclusivamente la Ley.

No obstante lo anterior, particularmente en materia de Crímenes de Lesa Humanidad, se puede constatar la gran dificultad que ha tenido el intérprete judicial para explicar el carácter vinculante, por ejemplo, de un tratado que ni firmó ni ratificó Colombia, a saber la Convención sobre la imprescriptibilidad de los de los crimenes de guerra y de los crímenes de lesa humanidad, y mucho menos de cómo se habría incorporadodichotratadoenelordenamientojurídicointerno. Ahora, si es que estamos pasando a un sistema no solamente acusatorio, sino de origen prácticamente anglosajón, basado en la costumbre y en el precedente judicial, incluyendo figuras no consagradas en la ley, sino propias del Derecho Internacional consuetudinario -a lo cual personalmente no me opongo-, muy respetuosamente sugeriría que el estudio y la incorporación del Derecho Internacional, bien sea de raigambre convencional o consuetudinaria, se hiciera de manera muchísimo más refinada, a fin de no distorsionarlo ni afectar de paso, tanto el Derecho interno como los derechos fundamentales, tanto de víctimas como de procesados.

\section{Algunas inconsistencias del Proyecto de Acto LEGISLATIVO.}

Retomando, ya en concreto, lo que tiene que ver con el proyecto que nos ocupa, no voy a insistir en algunos de los puntos que ya han sido debatidos, creo que con lujo de detalles y que llaman 
la atención de quienes hacen nuestras leyes. De hecho, celebro la preocupación del Dr. LozANo -aunque no se trata de hacerle campaña-, pero la celebro por estar presente, escuchando diversas opiniones y tomando apuntes; ojalá estas reflexiones pudieran ser discutidas en lo que resta del proceso legislativo con la Academia: me parece de la mayor importancia. Lo expreso así -cosa que ya he hecho con congresistas cuando se deciden a participar en foros o en programas de radio, o cuando simplemente se interesan por estos temas-, también a manera de sugerencia, porque muchas veces no se le presta atención a la complejidad y trascendencia de la tipificación de los Crímenes de Lesa Humanidad. En efecto, cuando discutimos el punto, en el mejor de los casos de pronto queda como tema de reflexión, pero hasta ahora nadie ha osado atender uno de los problemas fundamentales que seguirá subsistiendo en nuestro país por la falta de definición de esta categoría de delitos.

Veamos, en esta parte del proyecto, en el artículo tercero lo que se dice al respecto: "en ningún caso la Justicia Penal Militar conocerá de los crímenes de lesa humanidad", pero sin saber lo qué son o cuáles son... Lo que si sabemos es que es un asunto que no es de la competencia de la justicia penal militar. Y continúa dicho artículo afirmando que tampoco conocerá dicha jurisdicción "del delito de genocidio ni de delitos que de manera específica [lista que ha demostrado ser de una variable geometría a lo largo de este proceso], precisa y taxativa defina una ley estatutaria"1.

No obstante, avizoro una dificultad adicional, ¿por qué? Porque, como muchas veces ocurre en nuestro país, vamos a "inventarnos" los delitos, tanto las infracciones graves del régimen de Derecho Internacional Humanitario, que son taxativas, que están en los cuatro convenios de Ginebra, que es una obligación para Colombia incorporarlas, tipificarlas, investigarlas y sancionar a sus autores, al igual que los crímenes de lesa humanidad. Pues no diría que a inventar quizás, pero sí a tratar de traducir algunos de los crímenes de lesa humanidad, sin estar seguros de que allí estén todos, o haciendo distinciones que agregan una mayor confusión: ¿la tortura, la desaparición forzada, la violencia sexual, las ejecuciones extrajudiciales, o el desplazamiento forzado, constituyen una categoría diferente de los crímenes de lesa humanidad? Más aún, ¿no ocurren muchas veces precisamente como resultado de la

${ }^{1}$ Téngase en cuenta, al efecto, el texto aprobado durante el séptimo debate que aparece en el Anexo (Nota del Director). 
confrontación entre las partes y sería por ende un crimen de guerra o un delito de DIH?

A su vez, en el plano procesal, vamos a tener situaciones en las que un mismo individuo, susceptible de cometer Crímenes de Guerra, como para sintetizar, o infracciones graves a los cuatro convenios de Ginebra, para ser más preciso, también podría cometer de manera concomitante o subsecuente Crímenes de Lesa Humanidad. Es el ejemplo de quien hace uso de la fuerza letal contra un adversario que lo amenaza o ataca en el desarrollo de una operación militar o de combate, pero quien, asimismo, emplea dicha fuerza contra una persona que no participa directamente en las hostilidades, o adopta un comportamiento que definitivamente no hace parte de sus funciones. Entonces, habrá un problema de competencia, en el que el mismo individuo tendría que responder ante diferentes jurisdicciones.

Así, existirá la dificultad de que, no solamente se tratará de diferentes actos, sino de otros comportamientos que al mismo tiempo podrían constituir violaciones o infracciones graves, y al mismo tiempo de delitos que podrían ser considerados como Crímenes de Lesa Humanidad, por ejemplo en el caso del terrorismo. El uso del terrorismo o la diseminación del terror entre la población civil, proscritos por los Protocolos I y II, serían exclusivamente una transgresión del Derecho Internacional Humanitario o podrían configurar un Crimen de Lesa Humanidad...? Por cierto, ¿quién tiene la capacidad para cometer este tipo de delitos, los civiles insurrectos o también los militares y quién los juzgaría...?

Esa es sin duda una cuestión que no podremos resolver aquí, pero que incide trascendentalmente en términos de competencia personal al afirmar que, "cuando la conducta de los miembros de la fuerza pública en relación con un conflicto armado sea investigada y juzgada por las autoridades judiciales, se aplicará siempre el Derecho Internacional Humanitario". Si no son miembros de las fuerzas militares, sino que pertenecen a grupos armados ilegales o a entidades no estatales, ellos, por ser civiles no estarían sujetos a una corte marcial, aún cuando tengan la capacidad de infringir el Derecho Internacional Humanitario. En consecuencia, seguiremos teniendo dos jurisdicciones que van a conocer de infracciones al Derecho Internacional Humanitario, pero dependiendo de estatuto personal o de la pertenencia a un determinado grupo armado o la legalidad del mismo. En fin, en esas circunstancias, también habrá 
una concurrencia de jurisdicciones y de competencias, porque muy probablemente un mismo comportamiento podrá ser calificado como Crimen de Lesa Humanidad y como Crimen de Guerra, infracción o violación grave al DIH, además de las consideraciones relacionadas con la calidad de su autor o de su pertenencia a las fuerzas militares o a grupos armados ilegales.

\section{A MANERA DE CONCLUSIÓN.}

Yo quisiera, en los minutos que me restan, llamar de nuevo su atención sobre los denominados estándares. El representante de Naciones Unidas nos cita alguna "jurisprudencia" internacional -aunque realmente se refiere a otra cosa-relativa a los principios que redactó mi colega y amigo el profesor EMMANuEl DeCAux (hace apenas un mes conversábamos en un curso que dictamos en Brasil) en un informe relativo a [l]a administración de justicia por los Tribunales Militares. Se trata del informe adoptado por el Consejo Económico y Social el 13 de enero de 2006, el cual tengo conmigo en su versión en español. Pero, antes de continuar, vale la pena preguntarse ¿qué carácter vinculante tiene este documento, el de obligación internacional en términos convencionales o es una costumbre internacional? La verdad es que no es sino una recomendación, del más alto valor, pero de carácter formalmente no vinculante.

Veamos lo inscrito en los principios números 8 y 9: "Enjuiciamiento a los autores de violaciones graves a los Derechos Humanos". El primero se refiere a la competencia funcional de los órganos judiciales militares. $\mathrm{Y}$ en los dos casos se inicia la frase de la siguiente manera: "La competencia de los órganos judiciales militares debería [en condicional: should, no shall ni must] estar limitada a las infracciones cometidas dentro del ámbito estrictamente castrense por el personal militar". Ese principio lo adopta después de observar qué es lo que está pasando en el mundo, y es un principio que comparto. El segundo principio, el número nueve (9), afirma lo mismo y comienza de igual manera, pero "en todo caso, la competencia de los órganos judiciales militares debería excluirse en favor de la de los Tribunales de justicia ordinarios para instruir diligencias sobre violaciones graves de los Derechos Humanos, como las ejecuciones extrajudiciales, las desapariciones forzadas y la tortura, y para perseguir y juzgar a los autores de esos crímenes". También estoy de acuerdo con ello. Pero, el lenguaje y el carácter formal de este documento, es de recomendación porque quienes hacen el Derecho Internacional, nos guste o no, son los Estados. Por supuesto, entre ellos surgen 
diferencias y son los mismos Estados quienes designaron, a través de Naciones Unidas, un relator especial, un experto en el tema para hacer las recomendaciones, pero la obligación internacional, como tal, no existe. La cuestión de la determinación de la competencia y, en general, de la administración de la justicia penal militar, es algo que el Derecho Internacional ha dejado a los Estados.

Para resumir, corresponde al Estado decidir qué es lo que más le conviene, pero yo sí sugeriría que se hiciera de la forma más técnica y seria posible. Simplemente, para terminar, quisiera preguntarles a ustedes si conocen la jurisdicción suiza, la casa de los Convenios de Ginebra, por cierto. Su justicia penal militar, porque conozco de algunos casos, primero, también juzga a civiles, cuando se trata de materias de Genocidio y Crímenes de Lesa Humanidad. ¿Por qué?, porque han llegado excombatientes o exgenocidas de Ruanda, por ejemplo, o de otros países a territorio suizo, y es la jurisdicción militar la que se encuentra en mejor posición para entender la dimensión de una macro criminalidad de semejante naturaleza. Pero, ¿quién osaría afirmar que Suiza es un país violador de Derechos Humanos? Entonces, creo que en el fondo lo que hay aquí es un problema mucho más delicado. El problema es de desconfianza hacia la justicia penal militar colombiana, de manera merecida o no, pero ese es otro problema que, en todo caso, no resuelve el Proyecto de Acto Legislativo en cuestión. 